\title{
The Effect on Disc Height and Sagittal Alignment in 56 Consecutive Patients Undergoing Lateral Access Surgery
}

\author{
Donald A Deinlein ${ }^{1 *}$, Sakthivel Rajaram², Jorge L Perez ${ }^{3}$ and Mason B Frazier \\ ${ }^{1}$ Clinical Associate Professor, Primary Surgeon, University of Alabama at Birmingham, USA \\ ${ }^{2}$ Assistant Professor, Spine Fellow at Time/Data Collection, University of Alabama at Birmingham, USA \\ ${ }^{3}$ Research Fellow, Statistics, University of Alabama at Birmingham, USA \\ ${ }^{4}$ Assistant Professor, Independent Radiologist for Measurements, UAB, USA
}

*Corresponding author: Donald A Deinlein, MD, Clinical Associate Professor, University of Alabama at Birmingham, 960 Faculty Office Tower, 510 20th St South, Birmingham, Alabama, USA, Tel: 205-996-7258, Fax: 205-975-4701

\begin{abstract}
Study design: Retrospective study of 56 consecutive patients who underwent direct lateral interbody fusion.

Objective: Comparison of 3 graft composites and their effect on fusion rate, and the effect of interbody graft on disc height and spinopelvic parameters.

Summary of background data: The lateral approach to the spine, for spinal fusion, has gained interest from spine surgeons in recent years. The approach is less invasive, with less blood loss, decreased morbidity, and decreases length of stay in the hospital. The procedure has been shown to allow indirect decompression of the spinal canal and the intervertebral foramen. Segmental interbody arthrodesis may result in improved coronal and sagittal balance.

Methods: The results of 56 consecutive patients with 108 levels of pathology were operated on between 2008 and 2014 and were subsequently reviewed. The number of levels fused, the type of graft material used, the type fixation employed, the effect on disc height, regional lordosis and spino-pelvic parameters, and the number of complications were recorded.

Results: In conjunction with posterior pedicle screws BMP. $278 \%$, Autograft/BMA 75\%, DBX/BMA 82\% showed no significant difference in ability to achieve fusion. Anterior plating produced a $25 \%$ fusion rate and has been abandoned. The results demonstrated significant statistical improvement of disc height, increase in segmental and regional lordosis, SVA correction, and improved PI-LL. Complications, though frequent, appear transient and usually are not apparent by 6 months.
\end{abstract}

Conclusions: Direct lateral interbody fusion, though fraught with many early but temporary complications, has been found to effect indirect decompression by increasing disc height. Improved SVA, lumbar lordosis, and PI-LL difference were also noted.

\section{Introduction}

The lateral approach to the spine has gained interest from spine surgeons in recent years the approach is less invasive, with less blood loss, decreased morbidity, and decreases length of stay in the hospital. The procedure has been shown to allow indirect decompression of the spinal canal and the intervertebral foramen. Segmental interbody arthrodesis may result in improved coronal and sagittal balance. Interbody fusion has been reported by some to reduce discogenic pain but has been associated with increased morbidity with an open approach. 360 degree fusion has been shown to increase fusion rate but again with increased morbidity and increased spinal stiffness [1]. The trans-psoas approach may result in spinal nerve irritation as well as well as pain from the psoas muscle itself and may result in temporary thigh pain as well as permanent neural injury. These findings have prompted us to review our results.

\section{Methods}

After obtaining IRB approval, the results of 56 consecutive patients operated between 2008 and 2014

Citation: Deinlein DA, Rajaram S, Perez JL, Frazier MB (2019) The Effect on Disc Height and Sagittal Alignment in 56 Consecutive Patients Undergoing Lateral Access Surgery. Clin Arch Bone Joint Dis 2:009. doi.org/10.23937/2643-4091/1710009

Accepted: June 04, 2019: Published: June 06, 2019

Copyright: (C) 2019 Deinlein DA, et al. This is an open-access article distributed under the terms of the Creative Commons Attribution License, which permits unrestricted use, distribution, and reproduction in any medium, provided the original author and source are credited. 
were reviewed. Standard lateral approach through the external oblique, internal oblique, and transversalis fascia was employed followed by dilatation and insertion of a stabilized retractor allowing direct vision of the intervertebral disc. Clysdale implants (Medtronic) were used in all but one patient who had a previous discitis. This patient received a titanium cage. EMG monitoring was employed at all levels [2].

There were 108 spinal levels total. 26 patients had single level procedures, 13 had 2 level procedure, 13 had 3 level procedures. 3 had 4 levels and 1 had 6 levels performed. All except one patient had back up instrumentation. 8 patients received anterior plate fixation. 47 patients received posterior pedicle screw fixation. 6 of these were percutaneous with remainder receiving posterior-lateral fusion [3]. 21 patients received bone morphogenic protein-2 (BMP-2 Infuse Medtronic). 12 patients received autograft and bone marrow aspirate (BMA). 23 patients received demineralized bone matrix (DBX) and BMA [4].

13 patients underwent long fusions defined as instrumentation and fusion from L2 or above to L-5 or the sacrum. In general multiple interbody technique was reserved for those patients experiencing significant back or leg pain who demonstrated Schwab/SRS class P [5] sagittal balance. In this group, pelvic incidence, as well as pre-operative and post-operative sagittal vertical axis (SVA), pelvic incidence minus lumbat lordosis (PI-LL), pelvic tilt (PT), sacral slope (SS), and lumbar lordosis (LL) were measured and recorded.

Pre-operative and post-operative anterior and posterior disc heights were measured and recorded. In addition pre-operative and post-operative segmental and regional lordosis were also measured and recorded. Those patients who went on to fusion of all surgical levels were recorded as well as those who failed to fuse at least one level. All measurements and fusion determinations were made by an independent radiologist. Finally complications were reviewed and recorded.

Radiologic measurements: To measure preoperative and postoperative regional lordosis, the Cobb angle method was used on lateral radiographs, utilizing the Phillips iSite digital angle measurement tool. The superior endplate of $L 1$ and the superior endplate of $S 1$ were used as reference points for measurement. There were a few cases where T12-L1 was fused, and in these cases, the superior endplate of T12 was used for reference. In cases where there was fusion of L5-S1, the superior endplate of S1 was used for reference.

To measure preoperative and postoperative segmental lordosis, the Cobb angle method was used on lateral radiographs, utilizing Phillips iSite digital angle measurement tool. The superior and inferior endplates on either side of the fused levels were used as reference points for measurement. For example, if L2-L3 was fused, the superior endplate of $L 2$ and the inferior endplate of $L 3$ were used as reference points for measurement. If there was a multilevel fusion, for example L2$L 4$, the superior endplate of $L 2$ and the inferior endplate of $L 4$ were used as reference points for measurement.

To measure preoperative and postoperative anterior disc height, the distance between the anterior inferior and anterior superior endplate margins were measured on lateral radiographs utilizing Phillips isite digital line measurement tool.

To measure preoperative and postoperative posterior disc height, the distance between the posterior inferior and posterior superior endplate margins were measured on lateral radiographs utilizing Phillips iSite digital line measurement tool.

To determine whether ankylosis across the disc space had been achieved at the sites of fusion, AP and lateral radiographs were utilized to assess for radiographically visible ankylosis across the disc space. Ankylosis across the disc space that equaled, or exceeded, one third of the disc space on both PA and lateral radiographs was considered adequate ankylosis and/or fused.

Sagittal vertical axis (SVA), pelvic incidence minus lumbar lordosis (PI-LL), pelvic tilt (PT), sacral slope (SS), and lumbar lordosis (LL) were measured according to the methods of Legaye, et al. [6], and Schwab, et al. [5].

\section{Results}

The one stand alone procedure went on to fusion with excellent pain relief.

22 of 26 patients who underwent single level procedures were found to have solid fusions. 21 of 22 successful single level fusions were fixed posteriorly with pedicle screws. 5 single level procedures which were fixed anteriorly with plate/screw constructs went on to failure. DBX and BMA were used as graft material in all 5 . None sustained vertebral fracture. There was 1 successful fusion achieved with anterior plate/screw fixation which used autograft and BMA. 7 of 7 single level procedures utilizing DBX, BMA and pedicle screws achieved fusion. 7 of 8 single level procedures which utilized BMP2 went on to fusion. 6 of 7 with single level procedures utilizing BMA and autograft went on to fusion (Table 1 and Table 2).

8 of 13 two level fusions went on to solid fusion. 7 of 8 of these utilized pedicle screws, with 3 using BMP and 3 using BMA/DBX and I using BMA/Autograft. I case was fixed anteriorly with plate and screws and used BMA/Autograft. 4 of the failures utilized pedicle screw fixation 2 with BMP, 1 with BMA/Autograft and 1 with BMA/DBX. The other 2 level failure was with anterior screw/plate fixation with BMA/Autograft.

10 of 13 three level fusions went on to fusion. All 13 used pedicle screw fixation. Of the 10 who went on to 
Table 1: Graft type vs. fusion rate.

\begin{tabular}{|c|c|c|c|c|c|}
\hline \multirow[t]{2}{*}{ Graft } & & \multicolumn{2}{|c|}{ Fused } & \multirow[t]{2}{*}{ Total } & \multirow[t]{2}{*}{$\%$ Fused } \\
\hline & & no & yes & & \\
\hline BMP-2 & Stand alone & 0 & 1 & 1 & $100 \%$ \\
\hline \multirow[t]{3}{*}{ BMP-2 } & Pedicle Screws & 4 & 14 & 18 & $78 \%$ \\
\hline & Plate & 0 & 0 & 0 & $0 \%$ \\
\hline & Total & 4 & 14 & 18 & $78 \%$ \\
\hline \multirow[t]{3}{*}{ Auto/BMA } & Pedicel Screws & 3 & 9 & 12 & $75 \%$ \\
\hline & Plate & 1 & 2 & 3 & $67 \%$ \\
\hline & Total & 4 & 11 & 15 & $73 \%$ \\
\hline \multirow[t]{3}{*}{ BMA/DBX } & Pedicle Screws & 3 & 14 & 17 & $82 \%$ \\
\hline & Plate & 5 & 0 & 5 & $0 \%$ \\
\hline & Total & 8 & 14 & 22 & $64 \%$ \\
\hline \multirow[t]{3}{*}{ Total } & Pedicle Screws & 6 & 41 & 47 & $87 \%$ \\
\hline & Plate & 6 & 2 & 8 & $25 \%$ \\
\hline & Total & 13 & 43 & 56 & $77 \%$ \\
\hline
\end{tabular}

Table 2: Number of levels.

\begin{tabular}{|l|l|l|l|l|}
\hline Levels & Instrumentation & $\#$ & Fused & $\%$ \\
\hline 1 & & 26 & 22 & 85 \\
\hline & Pedicle screws & 22 & 21 & 95 \\
\hline & Anterior plate & 4 & 1 & 17 \\
\hline 2 & & 13 & 8 & 62 \\
\hline & Pedicle screws & 11 & 7 & 64 \\
\hline & Anterior plate & 2 & 1 & 50 \\
\hline 3 & Pedicle screws & 13 & 10 & 77 \\
\hline 4 & Pedicle screws & 3 & 2 & 67 \\
\hline 5 & Pedicle screws & 1 & 1 & 100 \\
\hline
\end{tabular}

fusion 4 used BMP, 4 BMA/DBX, and 2 BMA/Autograft. The 3 failures used BMP in 1 and 2 used BMA and DBX 2 of 3 four level procedures went on to fusion. Pedicle screw instrumentation was used in all three. All three used BMA/DBX as graft material.

The single 6 level procedure utilized pedicle screws and BMP and fused at all levels. In the long fusion group the pre-operative SVA was reduced on average from $6 \mathrm{~cm}$ to $3 \mathrm{~cm}$. PI-LL was reduced from a mean of $15^{\circ}$ to a mean of $9^{\circ}$. Pre-operative lumbar lordosis was increased from $34^{\circ}$ to $45^{\circ}$ on average. Pelvic tilt and sacral slope remained unchanged at PT $22^{\circ}$ and SS $29^{\circ}$ to $30^{\circ}$ respectively [7].

Anterior disc heights increased on average from $6^{\circ}$ to $13^{\circ}$ from pre to post-op, while posterior disc heights increased from $4^{\circ}$ to $8^{\circ}$. Segmental lordosis increased from $15^{\circ}$ pre-op to $21^{\circ}$ post-op. Regional lordosis increased from $36^{\circ}$ pre-op to $42^{\circ}$ post-op.

\section{Complications}

14 of 55, 25\%, complained of thigh pain. All but 2 resolved within 3 months. There were 5 patients who experienced a temporary neural deficit [4]. One was a patient with spinal dysraphism whose femoral nerve
Table 3: Complications.

\begin{tabular}{|l|l|l|}
\hline Complications & $\#$ & $\%$ \\
\hline Thigh Pain & 14 & 25 \\
\hline Pseudarthrosis & 13 & 23 \\
\hline Neural deficit & 5 & 9 \\
\hline PJK & 1 & 3.6 \\
\hline Bowel Injury & 1 & 1.8 \\
\hline Vascular Injury & 1 & 1.8 \\
\hline Neurogenic Bladder & 1 & 1.8 \\
\hline Muscle Weakness & 2 & 1.8 \\
\hline
\end{tabular}

was visually retracted during the procedure. In another a Kitner was lost during the procedure requiring enlarging the wound and probing until it was found. Another patient had a pedicle screw misplaced during an O-arm approach, requiring re-direction of the screw. Although there was no motor deficit the patient has complained of a persistent radiculopathy. One patient had $4 / 5$ strength of iliopsoas and quadriceps. And finally one patient required thrombectomy of the external iliac artery during an ancillary L5-S1 ALIF with temporary foot drop [8]. All patients improved to ambulatory status within 6 months (Table 3).

There was I patient who underwent a single level L1-2 DLIF and presented two weeks post-op with a perforated colon in the area of the surgical approach [9]. She was managed non-operatively and fully recovered. Whether this was an operative perforation or ruptured diverticulum could not be determined.

One patient who underwent a 2 level DLIF combined with a posterior decompression and fusion sustained a neurogenic bladder.

A patient with a 6 level DLIF and another with a 3 level DLIF plus 2 level ALIF both developed proximal junctional kyphosis and both required revision with extension into the upper thoracic spine [10].

\section{Discussion}

The results of our study would indicate that the is no significant difference between demineralized bone matrix and bone marrow aspirate (82\%), BMP-2 (78\%), or autograft $(73 \%)$ when performing an interbody fusion through a lateral approach when supplemented posteriorly with pedicle screw fixation (Table 1). One must be aware however that 40 of the patients also had posterior-lateral fusion. 6 patients underwent percutaneous pedicle screw fixation, 2 with BMP, and 3 with DBX and BMA with successful fusion (83\%). Only 1 patient with auto graft and BMA failed to obtain fusion in the percutaneous group.

In single level procedures $91 \%$ achieved fusion with any of the graft materials. It would appear that anterior fixation with a screw plate device is unwise when using DBX and BMA since all patients failed when using this 
Table 4: Disc height and lordosis measurements.

\begin{tabular}{|l|l|l|l|l|}
\hline Measurements & Pre-op & Post-op & p-value & difference \\
\hline Anterior Disc Height & $5.71 \pm 3.6$ & $12.45 \pm 3.4$ & $<0.001$ & $6.75 \mathrm{~mm}$ \\
\hline Posterior Disc Height & $4.21 \pm 2.3$ & $8.38 \pm 2.7$ & $<0.001$ & $4.17 \mathrm{~mm}$ \\
\hline Segmental Lordosis & $15.41 \pm 13.1$ & $21.4 \pm 15.3$ & $<0.001$ & $6.0^{\circ}$ \\
\hline Regional Lordosis & $36.3 \pm 13.8$ & $41.9 \pm 10.3$ & 0.001 & $5.6^{\circ}$ \\
\hline
\end{tabular}

Table 5: Spinopelvic parameters.

\begin{tabular}{|l|l|l|l|l|}
\hline Parameters & Mean & SD & p-value & Difference \\
\hline SVA pre & 7.0 & 5.9 & 0.013 & $3.4 \mathrm{~cm}$ \\
\hline SVA post & 3.6 & 2.7 & 0.013 & $3.4 \mathrm{~cm}$ \\
\hline PI-LL pre & 16.4 & 12 & 0.036 & $8.14^{\circ}$ \\
\hline PI-LL post & 8.3 & 6 & 0.036 & $8.14^{\circ}$ \\
\hline PT pre & 22 & 5 & 0.421 & $0.93^{\circ}$ \\
\hline PT post & 21 & 5 & 0.421 & $0.93^{\circ}$ \\
\hline SS pre & 28 & 11.5 & 0.152 & $1.86^{\circ}$ \\
\hline SS post & 30 & 9.6 & 0.152 & $1.86^{\circ}$ \\
\hline LL pre & 33 & 17.6 & 0.008 & $12.9^{\circ}$ \\
\hline LL post & 45 & 9.2 & 0.008 & $12.9^{\circ}$ \\
\hline Pelvic Incidence & 50 & 10 & $\mathrm{NA}$ & $\mathrm{NA}$ \\
\hline
\end{tabular}

combination [11]. Two level fusions were less reliable and failure was unrelated to type of graft or fixation. The same could be said for three level procedures. One case with 2 level anterior fixation failed in spite of using autograft and BMA. There was 1 successful 2 level anterior fixation which used autograft and BMA.

Anterior and posterior disc heights, segmental and regional lordosis measurements can be found in Table 4. Anterior disc height averaged and increase of 6.75 $\mathrm{mm}$ and posterior disc height $4.17 \mathrm{~mm}$. Segmental lordosis increased by 6 degrees and regional lordosis by 5.6 degrees. These procedures were performed prior to lordotic implants which are now available and may have improved results The measured values support the concept of indirect decompression [12,13].

13 patients underwent long fusions from the thoracolumbar junction to L-5 or S-1 (Table 5). The mean SVA improved from $7 \mathrm{~cm}$ to $3.5 \mathrm{~cm}$. The PI-LL deference improved from 16 degrees to 8 degrees. Mean lumbar lordosis improved from 33 degrees to 45 degrees. These procedures were limited to patients with SVA less than $9 \mathrm{~cm}$ and were combined with posterior decompression and posterior-lateral fusion [14]. None of the patients underwent anterior ligament release and no patients had a pure minimally invasive approach. All were hybrid procedures.

A $25 \%$ incidence of post-operative thigh pain has prompted a change in the operative approach from direct lateral to an oblique approach rather than a transpsoas approach. The incidence of thigh pain appears to have lessened however this group is not included in the study.
When performing multilevel procedures one should be cautious if stopping at the thoracolumbar junction as witnessed by the two patients who developed PJK and required revision to the upper thoracic spine. Such procedures result a multi-level rigid segment with a significant anterior vector at the upper end of the construct [15].

Although our changes in disc height, segmental lordosis, SVA, lumbar lordosis, and pelvic incidence - lumbar lordosis difference are statistically significant (Table 2), one may criticize our study in that we did not perform outcome studies which would added meaning to the radiologic measurements. Our fusion rate is lower than previous reports. Some levels were performed under supervision by inexperienced residents. Preparation of the disc space may have been a factor. The rigorous definition of a solid fusion may also play a roll [16-18].

\section{References}

1. Laws CJ, Coughlin DG, Lotz JC, Serhan HA, Hu SS (2012) Direct lateral approach to lumbar fusion is a biomechanically equivalent alternative to the anterior approach: An in vitro study. Spine 37: 819-825.

2. Uribe JS, Vale FL, Dakwar E (2010) Electromyographic monitoring and its anatomical implications in minimally invasive spine surgery. Spine 35: 368-374.

3. Anand N, Baron EM, Thaiyananthan G, Khalsa K, Goldstein TB (2008) Minimally invasive multilevel percutaneous correction and fusion for adult lumbar degenerative scoliosis: A technique and feasibility study. J Spinal Disord Tech 21: 459-467.

4. Lykissas MG, Aichmair A, Sama AA, Hughes AP, Lebl DR, et al. (2014) Nerve injury and recovery after lateral lumbar interbody fusion with and without bone morphogenetic protein-2 augmentation: A cohort-controlled study. Spine J 14: $217-224$.

5. Schwab F, Ungar B, Blondel, B, Buchowski J, Coe J, et al. (2012) Scoliosis research society schwab adult spinal deformity classification: A validation study. Spine 37: 10771082.

6. Legaye J, Duval-Beaupere G, Hecquet J, Marty C (1998) Pelvic incidence: A fundamental pelvic parameter for threedimensional regulation of spinal sagittal curves. Eur Spine J 7: 99-103.

7. Phan K, Rao PJ, Scherman DB, Dandie G, Mobbs RJ (2015) Lateral lumbar interbody fusion for sagittal balance correction and spinal deformity. J Clin Neurosci 22: 17141721.

8. Kueper J, Fantini GA, Walker BR, Aichmair A, Hughes AP (2015) Incidence of vascular complications during lateral lumbar interbody fusion: An examination of the mini-open access technique. Eur Spine J 24: 800-809. 
9. Balsano M, Carlucci S, Ose M, Boriani L (2015) A case report of a rare complication of bowel perforation in extreme lateral interbody fusion. Eur Spine J 24: 405-408.

10. Fujibayashi S, Kawakami N, Asazuma T, Ito M, Mizutani J, et al. (2017) Complications associated with lateral interbody fusion: Nationwide survey of 2998 cases during the first 2 years of its use in Japan. Spine 42: 1478-1484.

11. Le TV, Smith DA, Greenberg MS, Dakwar E, Baaj AA, et al. (2012) Complications of lateral plating in the minimally invasive lateral transpsoas approach. J Neurosurg Spine 16: 302-307.

12. Malham GM, Parker RM, Goss B, Blecher CM (2015) Clinical results and limitations of indirect decompression in spinal stenosis with laterally implanted interbody cages: results from a prospective cohort study. Eur Spine J 24 339-345.

13. Fujibayashi S, Richard A, Hynes RA, Otsuki B, Kimura H, et al. (2015) Effect of indirect neural decompression through oblique lateral interbody fusion for degenerative lumbar disease. Spine 4: 175-182.
14. Acosta FL Jr, Liu J, Slimack N, Moller D, Fessler R, et al. (2011) Changes in coronal and sagittal plane alignment following minimally invasive direct lateral interbody fusion for the treatment of degenerative lumbar disease in adults. J Neurosurg Spine 15: 92-96.

15. Berjano P, Balsano M, Buric J, Petruzzi M, Lamartina C (2012) Direct lateral access lumbar and thoracolumbar fusion: Preliminary results. Eur Spine J 21: 37-42.

16. Hu WK, He SS, Zhang SC, Liu YB, Li M, et al. (2011) An MRI study of psoas major and abdominal large vessels with respect to the X/DLIF approach. Eur Spine J 20: 557-562.

17. Kepler CK, Bogner EA, Herzog RJ, Huang RC (2011) Anatomy of the psoas muscle and lumbar plexus with respect to the surgical approach for lateral transpsoas interbody fusion. Eur Spine J 20: 550-556.

18. Dakwar E, Rifkin SI, Volcan IJ, Goodrich JA, Uribe JS (2011) Rhabdomyolysis and acute renal failure following minimally invasive spine surgery Report of 5 cases. J Neurosurg Spine 14: 785-788. 